\title{
Porosity measurements in suspension plasma sprayed YSZ coatings using NMR cryoporometry and $X$-ray microscopy
}

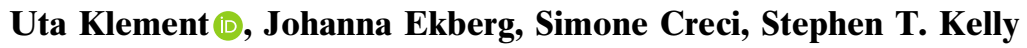

(C) The Author(s) 2018

\begin{abstract}
A large variety of coatings are used to protect structural engineering materials from corrosion, wear, and erosion, and to provide thermal insulation. In this work, yttria-stabilized zirconia coatings produced by suspension plasma spraying were investigated with respect to their microstructure and especially their porosity, as the porosity affects the thermal insulation of the underlying component. To determine porosity, pore size distribution, and pore shape, the coatings were investigated using novel advanced characterization techniques like NMR cryoporometry and X-ray microscopy. In general, the porosity is inhomogeneously distributed and the coatings showed a large variety of pore sizes ranging from a few nanometers to micrometers.
\end{abstract}

Keywords Yttrium-stabilized zirconium (YSZ), Porosity measurements, X-ray microscopy, NMR cryoporometry, SEM, Suspension plasma spraying

This paper was presented at the 13th Coatings Science International Conference (COSI) on June 26-30, 2017, in Noordwijk, The Netherlands.

U. Klement $(\bowtie)$, J. Ekberg

Industrial and Materials Science, Chalmers University of

Technology, 41296 Gothenburg, Sweden

e-mail: uta.klement@chalmers.se

S. Creci

Chemistry and Chemical Engineering, Chalmers University

of Technology, 41296 Gothenburg, Sweden

S. T. Kelly

Carl Zeiss X-ray Microscopy Inc., 4385 Hopyard Rd,

Pleasanton, CA 94588, USA

\section{Introduction}

Numerous techniques exist for determining porosity in porous materials, and the most commonly used methods for determining pore size distributions are image analysis (optical and electron microscopy), gas adsorption, and mercury intrusion porometry (MIP) ${ }^{1,2}$ However, there are also advanced characterization techniques like small and ultra-small angle scattering (U)SAS techniques, which provide uniquely useful information on the pore size and pore size distribution of both open and closed pores in size ranges from approximately $1 \mathrm{~nm}-10 \mu \mathrm{m} .{ }^{3}$ Due to limitations with the various techniques (e.g., accessibility of a particle accelerator or nuclear reactor), it is often valuable and frequently necessary to combine porosity and morphological information from different complementary techniques. In this work, the porosity of yttria-stabilized zirconia (YSZ) coatings is investigated using hitherto unusual methods such as nuclear magnetic resonance (NMR) cryoporometry and X-ray microscopy (XRM). NMR cryoporometry can be used to measure porosity, pore size distribution, and pore geometry in porous material and can measure pore sizes down to a few nanometers. ${ }^{1}$ But the technique is restricted to pore sizes of a few hundred nanometers. The porous material is saturated with a probe liquid and cooled down to complete solidification, and thereafter the temperature is slowly raised. The liquid will start to melt depending on pore size (smaller pore volumes will start to melt at lower temperature than larger), and when analyzing the fraction of liquid against temperature, it is possible to determine the pore size distribution. ${ }^{1} \mathrm{XRM}$ is an advanced imaging technique that visualizes the specimen in three dimensions (3D) using X-ray optics, while rotating the specimen in the X-ray beam. ${ }^{4}$ With this technique, it is possible to investigate internal features and quantitatively segment and analyze the porosity. 
The investigated samples are YSZ coatings commonly used as topcoats in thermal barrier coatings (TBCs). The coatings were produced by suspension plasma spraying (SPS), a relatively new plasma spraying technique which allows for the manufacture of finely structured coatings (nano- or submicron-sized) using a feedstock consisting of fine powder particles suspended in a liquid. The SPS technique has already proven to be capable of producing topcoats with good strain tolerance and heat insulative properties for TBCs used in gas turbine applications. ${ }^{5,6}$ Both properties are critical for the technological application as they determine the lifetime of the coating. The heat transfer primarily occurs by conduction through the bulk material. Hence, an important part in the assessment of SPS coatings is therefore the characterization of the microstructure and how it is built up. Features such as defects, interfaces, grain boundaries, and pores are important scattering sites for phonons and essential parts in the thermal insulation. ${ }^{7}$ But pore size distribution and pore geometry are also determining to what extent sintering occurs when the TBC is exposed to extreme temperatures $\left(\geq 1200^{\circ} \mathrm{C}\right)$ for extended time during operation of the engine., ${ }^{7,8}$ Smaller and/or nonspherical shaped pores have shorter diffusion paths and may therefore close more easily by sintering when exposed to high temperatures. To optimize the thermal properties and to maintain them during service of the components, it is important to have coatings with an optimized porosity. In fact, further performance improvements can be envisioned when tailoring the microstructure of the TBC system. Therefore, determination of pore size, pore size distribution, and pore geometry is an essential part in the coating design.

\section{Experimental}

The investigated YSZ coatings were produced by SPS using an Axial III high-power plasma torch (Northwest Mettech Corp., Vancouver, Canada) and a suspension consisting of $8 \mathrm{wt} \% \mathrm{YSZ}$ and ethanol. The solid content in the suspension was $25 \mathrm{wt} \%$, and the median size of the suspension particle was $500 \mathrm{~nm}$. Two coatings (coating 1 and 2) are described here, and their spraying process parameters are mentioned elsewhere. ${ }^{9}$ For structural investigations, scanning electron microscopy (SEM) was used on samples in cross section and in top view. NMR cryoporometry was performed using a Bruker Avance 600 spectrometer, and a ZEISS Xradia 810 Ultra X-ray microscope was applied for the XRM investigations. Prior to the NMR cryoporometry measurements, the YSZ coatings were separated from substrate and bond coat using aqua regia, cut into smaller pieces, and afterward packed densely in a $5 \mathrm{~mm}$ NMR tube. For XRM analysis, a pillar taken within a denser column of the YSZ coatings was prepared by removing the surrounding material using a Zeiss Auriga focused ion beam (FIB) instrument. The pillar $(18 \mu \mathrm{m}$ in diameter $)$ was visualized with true spatial resolution down to $50 \mathrm{~nm}$ and minimal voxel size of $32 \mathrm{~nm}$. More details about the NMR cryoporometry and XRM measurements are described elsewhere. ${ }^{10,11}$

\section{Results}

In Fig. 1, the YSZ coatings (coating 1 and 2) produced by SPS are presented in top view and in cross section at two different magnifications. More details on coating 2 can be found elsewhere. ${ }^{12}$ The coatings have a columnar structure with column widths of around $100 \mu \mathrm{m}$. The porosity is inhomogeneously distributed in both coatings (Fig. 1), and there seem to be more/larger pores in the inter-columnar regions. From the visual inspection (comparison of Figs. 1a and 1d), coating 2 seems to be more porous than coating 1 .

In Fig. 2, the pore size distribution versus pore radius as measured by NMR cryoporometry is presented for the two YSZ coatings. The amplitude of the pore size distribution curve is higher for coating 2 over the whole size range. Using values for the bulk density together with values from NMR cryoporometry, a porosity of 6.5 and 13 vol. \% was calculated for coating 1 and 2, respectively. The porosity values encompass all pores with a diameter between 8 and $400 \mathrm{~nm}$. Larger pores that can be found in the inter-columnar regions are not accessible by NMR cryoporometry due to limitations with the probe liquid properties and the instrumental hardware. As shown by Ekberg et al. ${ }^{10}$ duplicates of coatings 1 and 2 follow the same pore size distribution as shown in Fig. 2, demonstrating the reproducibility of the results. The pore size distribution as obtained by NMR cryoporometry (Fig. 2) reveals that both coatings contain a large amount of pores in the smaller size range, i.e., below $10 \mathrm{~nm}$. Coating 2 contains also a substantial amount of pores with a radius of $30-50 \mathrm{~nm}$, while this size range is more or less absent in coating 1.

One advantage of NMR cryoporometry is the possibility to also obtain information on the pore geometry within the coating. By comparing the freezing and cooling curves for the probe liquid within the porous sample, the pore geometry can be approximated to the pore shape having the best curve fit. Pores in coating 1 show spherical-like pore shapes over the complete size range. Coating 2 is approximated with a cylindrical pore shape for pores below $200 \mathrm{~nm}$ in radius (here, the cylinder radius is considered) while a spherical-like pore shape is used for describing the larger pores $(>200 \mathrm{~nm})$.

Using XRM, tomographic imaging of the specimen was carried out in both the large field of view (LFOV) and high resolution (HRES) magnification levels. Following acquisition of the tomographic data, the 2D radiographs were aligned and reconstructed into $3 \mathrm{D}$ data sets. Figure 3 a shows a $3 \mathrm{D}$ reconstruction of 

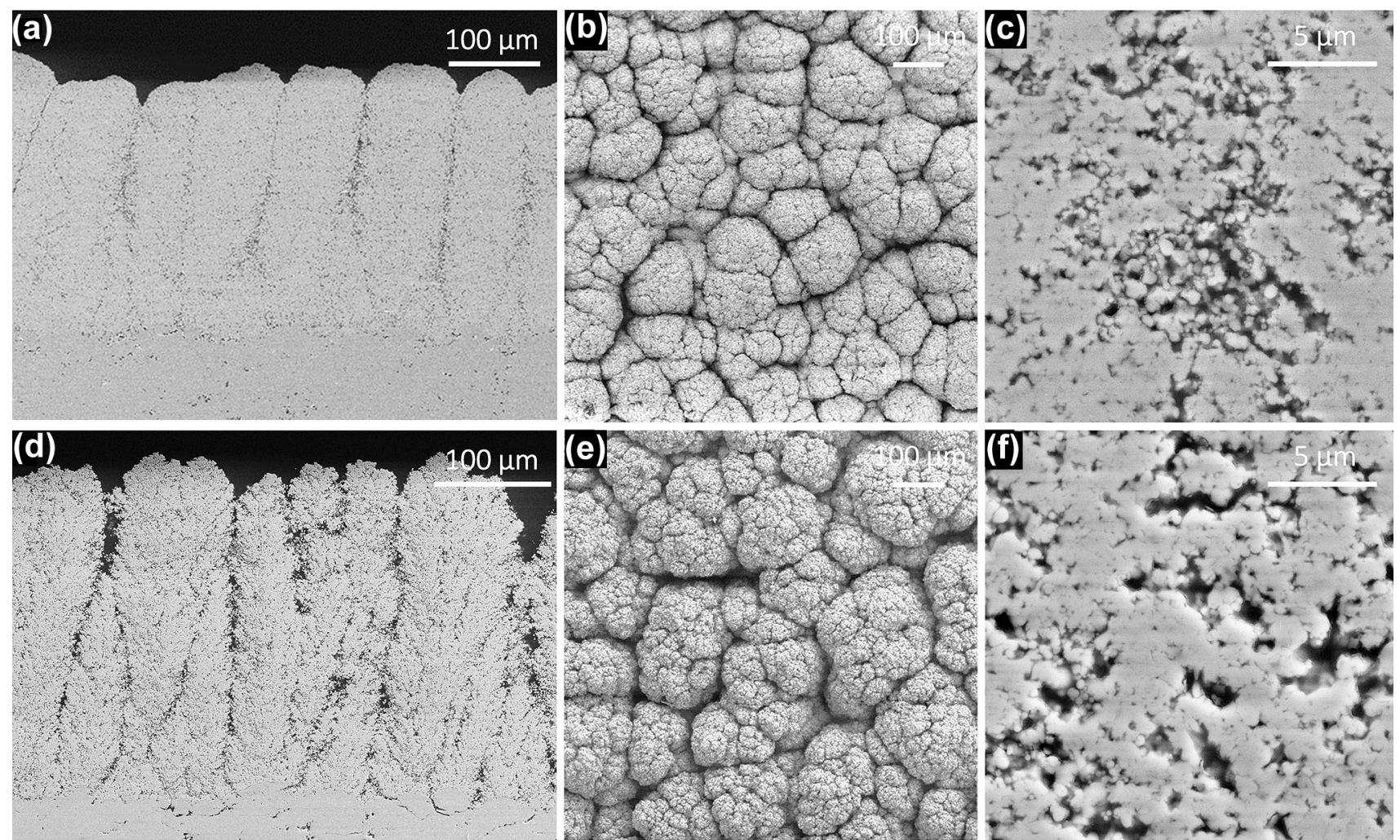

Fig. 1: SEM micrographs of the suspension plasma sprayed YSZ coatings [coating 1 (a-c) and coating 2 (d-f)] in: (a and d) cross section; (b and e) top view; (c and f) cross section of the inter-columnar area at higher magnification

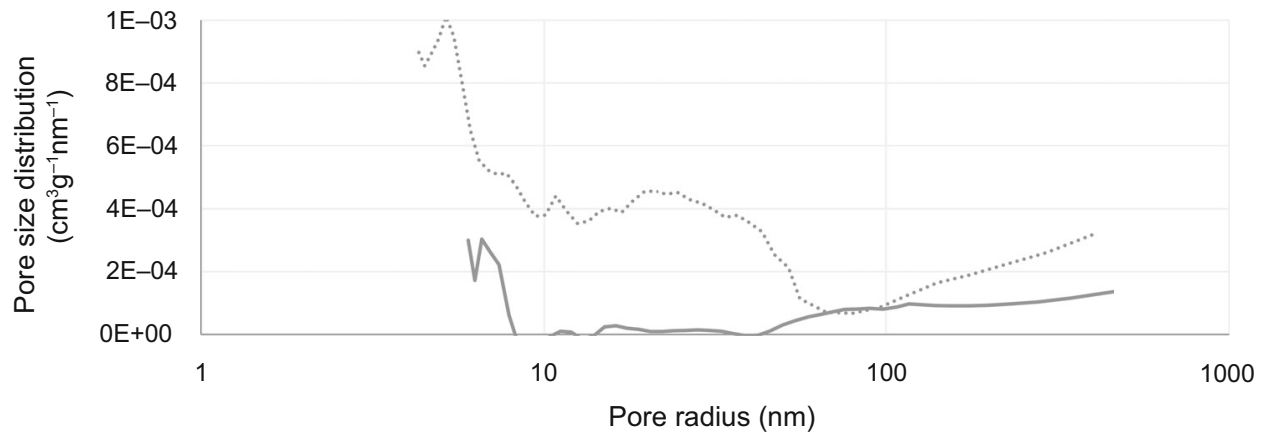

Fig. 2: Pore size distributions obtained by NMR cryoporometry for two samples, coating $1(-)$ and coating 2 ( $\cdots)$

the analyzed volume illustrating the complex pore structure in coating 2. In the 2D HRES absorption contrast image in Fig. 3b, the sizes of different pores are determined. The smallest pore diameter measured/ resolved in this case is $50 \mathrm{~nm}$. (The pore size distribution was only measured for the closed pores and not for the open connected pores. Hence, the largest pore size included in the measured volume is not known.) In the analyzed volume, the total porosity is determined to be 13 vol. \% of which $11 \%$ is derived from closed pores (1.4 vol. \%). When using phase contrast images, dark to bright intensity fringes highlight the edges and boundaries of the YSZ microstructure. Because of the different refractive indexes between the YSZ and the pore space, the interior of the pores becomes highlighted with a darker outline. On small pores, this creates an effect of darkening the overall intensity of the pore. All renderings and measurements of the 3D nanoscale XRM data were done with the Visual SI Advanced software package (Object Research Systems, Canada); see also Klement et al. ${ }^{11}$ 
(a)
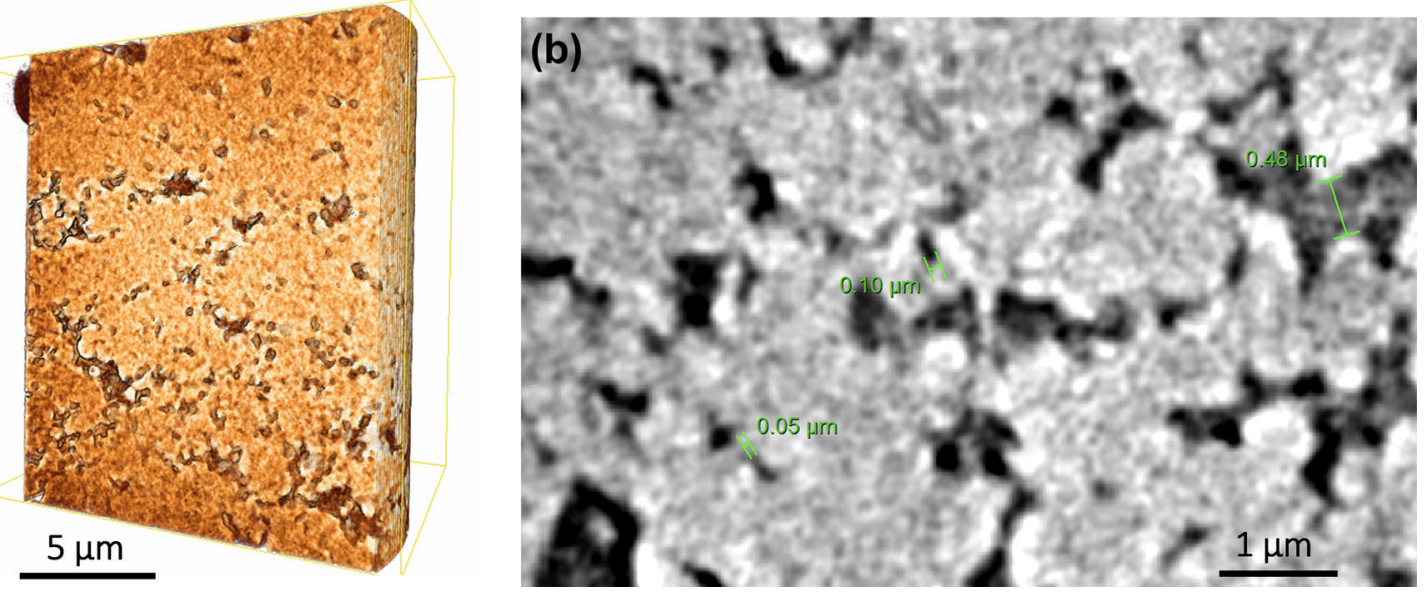

Fig. 3: (a) 3D reconstruction of the suspension plasma sprayed YSZ coating (coating 2) as obtained by the Zeiss Xradia 810 Ultra X-ray microscope (XRM). (b) 2D HRES absorption contrast image with measured pores sizes

\section{Discussion}

The YSZ coatings produced by SPS have a columnar structure, and porosity is affected by the process parameters used during the spraying process. As shown by Ganvir et al. ${ }^{13}$ the porosity content seems to be decisive for the thermal conductivity. Commonly, mercury intrusion porosimetry (MIP) is used for porosity measurements. The pore size distribution is determined based on the external pressure needed to force the liquid into the pore, and the MIP technique is able to measure open pores over a wide size range, i.e., from $3 \mathrm{~nm}$ to $300 \mu \mathrm{m}$. $^{1}$ However, the use of MIP is increasingly restricted because of environmental reasons. Moreover, the achievable coating properties are also influenced by pore morphology, which is not accessible in this way. In comparison with MIP, XRM has the advantage of being an imaging technique, which allows for the reconstruction of the analyzed volume. Hence, a 3D reconstruction of the pore space can be achieved which, in addition to dedicated analysis, enables a visual impression of the complex pore shapes. With help of image analysis, the fraction of open and closed porosity in coating 2 could be determined to be $89 \%$ and $11 \%$, respectively (total porosity is $13 \mathrm{vol} . \%)$. Pore size distribution and pore morphology could also be determined by NMR cryoporometry. In this case, only an approximation of the pore shape was done but much smaller pores (down to $8 \mathrm{~nm}$ in pore diameter) were accessible. NMR cryoporometry can measure open and connected porosity but cannot access the closed pores. Hence, even though the porosity values achieved by XRM and NMR cryoporometry are similar, i.e., both techniques provided a porosity of 13 vol. \% for coating 2, they are not directly comparable. This is mainly due to the difference in sample volume analyzed. While a larger sample volume can be analyzed by NMR cryoporom- etry, only a small portion of the sample (here a pillar with a diameter of $18 \mu \mathrm{m}$ ) is analyzed by XRM. Hence, XRM provides valuable 3D information on the (local) porosity. The good agreement in the obtained porosity values from the two measuring techniques is due to the fact that the coatings contain a majority of open and connected pores. The limited size range (down to $50 \mathrm{~nm}$ ) in XRM seems to be balanced by the accessibility of closed pores. Note that the total porosity of 13 vol.\% measured by NMR cryoporometry refers to pores ranging from $8 \mathrm{~nm}$ to $400 \mathrm{~nm}$ in size. If the pore size range is limited to $50 \mathrm{~nm}$ (for better comparison with XRM), total porosity is reduced to $11 \mathrm{vol} \%$. This shows that a large number of nanopores are present in coating 2 .

There are advantages and disadvantages with all the measurement techniques. Nevertheless, novel techniques such as XRM and NMR cryoporometry provide complementary data that extend our ability to quantitatively describe the pore space in SPS coatings. To be able to optimize the thermal properties and to maintain them during service of the components, it will be important to make ready use of such advanced characterization techniques in TBC design.

\section{Conclusions}

- Suspension plasma spraying provides highly porous coatings; porosity can be tailored by the spraying parameters.

- XRM can image the (local) porosity within the coating in 3D at a resolution down to $50 \mathrm{~nm}$.

- NMR cryoporometry allows for the determination of porosity and pore size distribution (from a few nanometer up to a micrometer) and is capable of providing information about the pore geometry. 
Acknowledgments The authors would like to thank S. Björklund and A. Ganvir at University West, Trollhättan, Sweden, for preparing the samples. Thanks to Assoc. Prof. L. Nordstierna, Chalmers University of Technology, for assisting with the NMR cryoporometry measurements at the Swedish NMR Centre, Göteborg, Sweden. Västra Götalandsregionen financially supported this work in connection with the PROSAM project.

Open Access This article is distributed under the terms of the Creative Commons Attribution 4.0 International License (http://creativecommons.org/li censes/by/4.0/), which permits unrestricted use, distri bution, and reproduction in any medium, provided you give appropriate credit to the original author(s) and the source, provide a link to the Creative Commons license, and indicate if changes were made.

\section{References}

1. Petrov, OV, Furó, I, "NMR Cryoporometry: Principles, Applications and Potential." Prog. Nucl. Magn. Reson. Spectrosc., 54 (2) 97-122 (2009)

2. Wong, P-Z, Methods of the Physics of Porous Media. Academic Press, London (1999)

3. Anovitz, LM, Cole, DR, "Characterization and Analysis of Porosity and Pore Structures." Reviews in Mineralogy and Geochemistry, 80 (1) 61-164 (2015)

4. Merkle, AP, Gelb, J, "The Ascent of 3D X-ray Microscopy in the Laboratory." Micros. Today, 21 10-15 (2013)
5. Miller, RA, "Thermal Barrier Coatings for Aircraft Engines: History and Directions." J. Therm. Spray Technol., 6 (1) 3542 (1995)

6. Beele, W, Marijnissen, G, van Lieshout, A, "The Evolution of Thermal Barrier Coatings-Status and Upcoming Solutions for Today's Key Issues." Surf. Coatings Technol., 120121 61-67 (1999)

7. Golosnoy, IO, Cipitria, A, Clyne, TW, "Heat Transfer Through Plasma-Sprayed Thermal Barrier Coatings in Gas Turbines: A Review of Recent Work.' J. Therm. Spray Technol., 18 (5-6) 809-821 (2009)

8. Curry, N, "Design of Thermal Barrier Coatings." Ph.D. Thesis, University West, 2014

9. Ganvir, A, Curry, N, Markocsan, N, Nylén, P, Vilemova, M, Pala, Z, "Influence of Microstructure on Thermal Properties of Columnar Axial Suspension Plasma Sprayed Thermal Barrier Coatings." J. Therm. Spray Technol., 25 (1-2) 202212 (2015)

10. Ekberg, J, Nordstierna, L, Klement, U, "Porosity Investigation of Yttria-Stabilized Zirconia Topcoats Using NMR Cryoporometry." Surf. Coatings Technol., 315 468-474 (2017)

11. Klement, U, Ekberg, J, Kelly, ST, “3D Analysis of Porosity in a Ceramic Coating Using X-ray Microscopy." J. Therm. Spray Technol., 26 (3) 456-463 (2017)

12. Klement, U, Ekberg, J, Ganvir, A, "EBSD Analysis and Assessment of Porosity in Thermal Barrier Coatings Produced by Axial Suspension Plasma Spraying (ASPS)." Mater. Sci. Forum, 879 972-977 (2017)

13. Ganvir, A, Curry, N, Björklund, S, Markocsan, N, Nylén, P, "Characterization of Microstructure and Thermal Properties of YSZ Coatings Obtained by Axial Suspension Plasma Spraying (ASPS)." J. Therm. Spray Technol., 24 (7) 11951204 (2015) 